\title{
Atherosclerotic Lesion Progression Changes Lysophosphatidic Acid Homeostasis to Favor its Accumulation
}

\author{
Martine Bot, ${ }^{*}$ Ilze Bot, ${ }^{*}$ Rubén Lopez-Vales, ${ }^{\dagger \neq}$ \\ Chris H.A. van de Lest, §प \\ Jean Sébastien Saulnier-Blache," \\ J. Bernd Helms, ${ }^{\S}$ Samuel David, ${ }^{\dagger}$ \\ Theo J.C. van Berkel, ${ }^{\star}$ and Erik A.L. Biessen*,** \\ From the Division of Biopharmaceutics, ${ }^{*}$ Gorlaeus Laboratories, \\ Leiden University, Leiden, The Netherlands; the Centre for \\ Research in Neuroscience, ${ }^{\dagger}$ Research Institute of the McGill \\ University Health Center, Montreal, Quebec, Canada; the \\ Departament de Biologia Cel.lular, Fisiologia i Immunologia, \\ Institut de Neurociències, Centro de Investigación Biomédica en \\ Red sobre Enfermedades Neurodegenerativas (CIBERNED), \\ Universitat Autònoma de Barcelona, Bellaterra, Catalonia, \\ Spain; the Department of Biochemistry and Cell Biology, ${ }^{\S}$ and the \\ Department of Equine Sciences, Faculty of Veterinary Medicine, ${ }^{\text {"T }}$ \\ Utrecht University, Utrecht, The Netherlands; Inserm U858/I2MR, \\ the Department of Metabolism and Obesity," Cedex, France; and \\ the Experimental Vascular Pathology Group, the Department of \\ Pathology,*: Maastricht University Medical Center, Maastricht, \\ The Netherlands
}

Lysophosphatidic acid (LPA) accumulates in the central atheroma of human atherosclerotic plaques and is the primary platelet-activating lipid constituent of plaques. Here, we investigated the enzymatic regulation of LPA homeostasis in atherosclerotic lesions at various stages of disease progression. Atherosclerotic lesions were induced in carotid arteries of low-density lipoprotein receptor-deficient mice by semiconstrictive collar placement. At 2 -week intervals after collar placement, lipids and RNA were extracted from the vessel segments carrying the plaque. Enzymaticand liquid chromatography-mass spectrometry-based lipid profiling revealed progressive accumulation of LPA species in atherosclerotic tissue preceded by an increase in lysophosphatidylcholine, a precursor in LPA synthesis. Plaque expression of LPA-generating enzymes cytoplasmic phospholipase $A_{2}$ IVA (cPLA $A_{2}$ IVA) and calcium-independent PLA 2 VIA (iPLA 2 VIA) was gradually increased, whereas that of the LPA-hydrolyzing enzyme LPA acyltransferase $\alpha$ was quenched. Increased expression of CPLA $A_{2} I V A$ and iPLA ${ }_{2}$ VIA in advanced lesions was confirmed by immunohistochemistry. Moreover, LPA receptors 1 and 2 were 50\% decreased and sevenfold upregulated, respectively. Therefore, key proteins in LPA homeostasis are increasingly dysregulated in the plaque during atherogenesis, favoring intracellular LPA production. This might at least partly explain the observed progressive accumulation of this thrombogenic proinflammatory lipid in human and mouse plaques. Thus, intervention in the enzymatic LPA production may be an attractive measure to lower intraplaque LPA content, thereby reducing plaque progression and thrombogenicity. (Am J Patbol 2010, 176:3073-3084; DOI: 10.2353/ajpath.2010.090009)

Cardiovascular diseases continue to be one of the major causes of death in Western society. They are often attributable to the development in middle-sized and large arteries of vulnerable atherosclerotic lesions consisting of a lipid core and an overlying thin fibrous cap. ${ }^{1,2}$ On rupture of the fibrous cap, the plaque thrombogenic content will be exposed to the blood circulation and trigger the coagulation cascade, leading to thrombus formation and acute coronary syndromes., ${ }^{3,4}$ One of the major thrombogenic constituents of the lipid core was demonstrated to be lysophosphatidic acid (LPA). ${ }^{5-7}$

LPA is a bioactive lipid that was originally viewed as a key intermediate in de novo lipid synthesis but has

Supported by grant TSN2004.001 from the Netherlands Thrombosis Foundation (to M.B.), grant 916.86.046 from the Netherlands Organization for Scientific Research (to I.B.), and grant 2003T201 from the Netherlands Heart Foundation (to E.B.). The authors belong to the European Vascular Genomics Network, a Network of Excellence supported by the European Community's Sixth Framework Program for Research Priority 1 (Life Sciences, Genomics, and Biotechnology for Health; contract LSHM-CT-2003-503254).

M.B. and I.B. contributed equally to this study.

Accepted for publication January 28, 2010.

Address reprint requests to Martine Bot, Ph.D., Division of Biopharmaceutics, Leiden/Amsterdam Center for Drug Research, Gorlaeus Laboratories, Leiden University, Einsteinweg 55, 2333 CC Leiden, The Netherlands. E-mail: m.bot@lacdr.leidenuniv.nl. 
emerged as an intra- and intercellular phospholipid messenger with a variety of biological activities. ${ }^{8}$ LPA has pleiotropic effects on blood cells and various cell types of the vessel wall. For instance, LPA mediates multiple cellular processes that are instrumental in atherogenesis, including smooth muscle contraction, ${ }^{9,10}$ endothelial/leukocyte interaction, ${ }^{11}$ platelet aggregation, ${ }^{5}$ and cell proliferation, ${ }^{12,13}$ all processes relevant to atherosclerosis. Indeed, evidence is accumulating that LPA can aggravate cardiovascular diseases by virtue of its athero- as well as thrombogenic activity. ${ }^{7,14}$

LPA exerts its effects through specific $G$ protein-coupled receptors, such as LPA receptor 1,2 , and $3\left(\mathrm{LPA}_{1-3}\right)$, which belong to the endothelial differentiation gene family, and the genetically more distant $\mathrm{LPA}_{4}$ (GPR23) and LPA (GPR92). ${ }^{15-18}$ Furthermore, studies have revealed a direct role for LPA as peroxisome proliferator-activated receptor (PPAR) $\gamma$ agonist, regulating the expression of genes that contain PPAR response elements. ${ }^{7}$ The CD36 promoter was found to contain such PPAR response elements, rendering it sensitive to LPA-induced transcriptional upregulation of CD36 in macrophages. Indeed, Zhang et al have shown that LPA induces neointima formation via PPARy activation and CD36 upregulation. ${ }^{19}$

LPA is formed during mild oxidation of low-density lipoprotein (LDL) and was found to be the main plateletactivating lipid constituent of LDL. ${ }^{5,20}$ It is in part directly deposited in the plaque by mildly oxidized LDL retained in the subendothelial matrix. ${ }^{21}$ However, LPA can also be formed in situ from phosphoglycerides by macrophages and smooth muscle cells that are present in the developing atherosclerotic lesion. ${ }^{22}$ Therefore, in addition to LDLmediated influx of LPA into the lesion, a dysbalance in cellular LPA homeostasis may also result in progressive build-up of LPA in atherosclerotic lesions. Overall, LPA accumulates progressively in the lipid-rich core of atherosclerotic plaques and is considered the primary platelet-activating lipid constituent of the plaque. Thus, LPA could well be an important risk factor of intraarterial thrombus formation in later stages of atherogenesis. ${ }^{7,14}$

In this study, we aimed to delineate the intracellular enzymatic regulation of LPA homeostasis within atherosclerotic lesions of Western-type diet-fed LDL receptor deficient $\left(\mathrm{LDLr}^{-1-}\right)$ mice. We are the first to demonstrate that also in $\mathrm{LDLr}^{-1-}$ mice, LPA progressively accumulates in carotid artery plaques as has previously been shown for human atherosclerotic tissue. RNA analysis of plaque material from these mice provides evidence that LPA homeostasis indeed is altered during atherosclerotic lesion development, favoring intracellular LPA accumulation. This leads us to propose that intervention in the LPA metabolism could be an effective new strategy in reducing plaque thrombogenicity.

\section{Materials and Methods}

\section{Animals}

All animal work was approved by the regulatory authority of Leiden University and performed in compliance with
Dutch government guidelines. Male $\mathrm{LDLr}^{-1-}$ mice, obtained from Jackson Laboratories and bred in our local animal breeding facility, were fed a Western type diet containing $0.25 \%$ cholesterol and $15 \%$ cacaobutter (Special Diet Services, Sussex, UK) two weeks before surgery and throughout the experiment. To determine the LPA content of and gene expression levels in mouse plaques (respectively $n=16$ and $n=20$ ), atherosclerotic carotid artery lesions were induced by perivascular collar placement as described previously. ${ }^{23}$ During the experiments, total serum cholesterol levels were quantified colorometrically by enzymatic procedures using Precipath (Roche Diagnostics GmbH, Mannheim, Germany) as internal standard. Total plasma cholesterol levels between groups did not differ.

\section{Tissue Harvesting}

LPA content and gene expression profiles of carotid artery plaques in $\mathrm{LDLr}^{-1-}$ mice were determined at 0 to 8 weeks after perivascular collar placement. ${ }^{23}$ Hereto, a subset of four mice was sacrificed by perfusion through the left cardiac ventricle with phosphate-buffered saline (PBS). Subsequently, both common carotid arteries were excised and snap-frozen in liquid nitrogen for optimal RNA and lipid preservation. The specimens were stored at $-80^{\circ} \mathrm{C}$ until further use. For immunohistochemistry animals were sacrificed at 6 weeks after collar placement. Mice were subjected to in situ perfusion-fixation with PBS and subsequently $4 \%$ Zinc Formalfixx (Shandon Inc). The carotid arteries were removed and after overnight fixation stored at $-20^{\circ} \mathrm{C}$ until further use. Transverse $5-\mu \mathrm{m}$ cryosections were prepared in a proximal direction from the carotid bifurcation and mounted in order on a parallel series of slides.

\section{Lipid Extraction from Plaque Material}

Lipids were extracted from carotid artery segments containing the plaque by a modified Bligh and Dyer proto$\mathrm{col}^{24}$ and a subsequent 1-butanol extraction step for optimal recovery of the lysophospholipids as described previously. ${ }^{25,26}$ In short, two to three carotid artery plaque samples were pooled and homogenized in $0.5 \mathrm{ml}$ distilled, $\mathrm{N}_{2}$ flushed water using a mechanical potter and used for lipid extraction. All solvents were evaporated under nitrogen, and extracted lipids were dissolved in PBS $+0.1 \%$ bovine serum albumin (fatty acid free, Sigma, Zwijndrecht, The Netherlands) by sonication (MSE Soniprep 150, 18 amplitude microns) for $20 \mathrm{sec}$ onds on ice and under argon.

\section{LPA Quantification}

LPA content of the plaque lipid extracts, from $0,2,4$, and 8 weeks after collar placement, was determined in a highly sensitive radio-enzymatic assay as described previously, ${ }^{27}$ which is based on recombinant rat LPA acyltransferase (LPAAT) catalyzed conversion of LPA and alkyl-LPA into $\left[{ }^{14} \mathrm{C}\right] \mathrm{PA}$ in the presence of $\left[{ }^{14} \mathrm{C}\right]$ Oleoyl- 
Table 1. RT-PCR Primer Sequences and Sources

\begin{tabular}{|c|c|c|c|}
\hline Gene & Source & Forward primer & Reverse primer \\
\hline$L P A_{1}$ & NM_010336 & 5'-TGTCCTGGCCTATGAGAAGTTCT-3' & 5'-TTGTCGCGGTAGGAGTAGATGA-3' \\
\hline$L P A_{2}$ & NM_020028 & 5'-CTCACTGGTCAATGCAGTGGTATAT-3' & 5'-GAAGGCGGCGGAAGGT-3' \\
\hline$L P A_{3}$ & NM_022983 & 5'-GGGACGTTCTTCTGCCTCTTTA-3' & 5'-GAAAGTGGAACTTCCGGTTTGT-3' \\
\hline GPR23 & NM_175271 & 5'-GATGGAGTCGCTGTTTAAGACTGA-3' & 5'-TGTTTGATCACTAACTTCCTCTTGGATA-3' \\
\hline LPAAT $\alpha$ & BC009651 & 5'-TCCCTCGACCTGCTTGGA-3' & 5'-CATAGTAGCTCACGCTTGGCAAT-3' \\
\hline$\angle P A P$ & AF216223 & $5^{\prime}$-AAATGGCCCCCATTTGCT-3' & 5'-TGCACAAACCACTCCTTAGATTCTT-3' \\
\hline$P L D_{1}$ & XM_130807 & $5^{\prime}$-GACTCTGCCTGTGACCGTGAT-3' & 5'-CCAGATGCATAAATGAACCTAAGAAC-3' \\
\hline$P L D_{2}$ & NM_008876 & 5'-GCCAGCAAACAGAAATACTTGGA-3' & 5'-GGCGTGGTAATTGCGATAGAA-3' \\
\hline$\angle P P 1$ & AY247795 & 5'-CATGCTGTTTGTCGCACTTTATCT-3' & 5'-AAACTGGAGCATGGGTCGTAA-3' \\
\hline FABP1 & BC009812 & 5'-GAACTTCTCCGGCAAGTACCAA-3' & 5'-GGCAGACCTATTGCCTTCATG-3' \\
\hline$F A B P 2$ & BC013457 & $5^{\prime}-$ AGCAACGCTGAAGAGCTAAGCT-3' & $5^{\prime}$-CCAGTGCTGATAGGATGACGAA-3' \\
\hline FABP3 & BC002082 & $5^{\prime}-$ ACTCGGTGTGGGCTTTGC -3 & 5'-TATCCCCGTTCTTCTCGATGAT-3' \\
\hline FABP4 & BC054426 & $5^{\prime}$-GCGTGGAATTCGATGAAATCA-3' & $5^{\prime}$-CCCGCCATCTAGGGTTATGA-3' \\
\hline FABP5 & BC002008 & $5^{\prime}$-GGAAGGAGAGCACGATAACAAGA-3' & 5'-GGTGGCATTGTTCATGACACA-3' \\
\hline CPLA2IVA & NM_008869 & 5'-GGATGAGCATGACCCTGAGTAGTT-3' & 5'-GAGACACGTGAAGAGAGGCAAAG-3' \\
\hline iPLA2VIA & NM_016915 & 5'-TCCATGAGTACAATCAGGACATGAT-3' & 5'-AGAAACGACTATGGAGAGTTTCTTCAC-3' \\
\hline PPAR $\gamma$ & NM_011146 & 5'-CATGCTTGTGAAGGATGCAAG-3' & 5'-TTCTGAAACCGACAGTACTGACAT-3' \\
\hline CD36 & NM_007643 & 5'-GTTCTTCCAGCCAATGCCTTT-3' & 5'-ATGTCTAGCACACCATAAGATGTACAGTT-3' \\
\hline CD68 & NM_009853 & $5^{\prime}-$ CCTCCACCCTCGCCTAGTC-3' & 5'-TTGGGTATAGGATTCGGATTTGA-3' \\
\hline$\alpha$-actin & NM_007392 & 5'-TCCCTGGAGAAGAGCTACGAACT-3' & $5^{\prime}$ - GATGCCCGCTGACTCCAT-3' \\
\hline$N M-M H C$ & AK040822 & 5'-TTTGGATGGCAGGTTATAAGGAA-3, & 5'-GATAACGACCATGCATCCTACAGT-3' \\
\hline HPRT & NM_013556 & $5^{\prime}$-TTGCTCGAGATGTCATGAAGGA-3' & $5^{\prime}-$ AGCAGGTCAGCAAAGAACTTATAG- $3^{\prime}$ \\
\hline Cyclophilin A & AK0̄10338 & 5'-CCATTTCAAGAAGCAGCGTTT-3' & 5'-ATTTTGTCTTAACTGGTGGGTCTGT-3' \\
\hline
\end{tabular}

CoA. Resulting lipid mixture was subjected to two-dimensional thin-layer chromatography and the radiolabeled products identified by comigration with unlabeled lipid and subsequent visualization by iodine staining. $\left[{ }^{14} \mathrm{C}\right] \mathrm{PA}$ spots were scraped and the silica pools were counted for radioactivity after suspending in scintillation cocktail, after which the LPA content (in picomoles) was calculated from the radioactivity. ${ }^{27}$

\section{Mass Spectrometry}

Mass spectrometric analysis was performed essentially as described earlier. ${ }^{28}$ Before mass spectroscopy, lipid molecular species were separated by high-performance liquid chromatography. For this the lipid extracts were dissolved in methanol/acetonitrile/chloroform/water (46: 20:17:17). Separation was performed on a Synergi $4 \mu \mathrm{m}$ MAX-RP 18A column $(250 \times 3 \mathrm{~mm}$; Phenomenex, CA $)$. Elution was performed with a linear gradient of water in methanol/acetonitrile (60:40 v/v) decreasing from 12.5\% to $0 \%$ in 25 minutes, followed by further isocratic elution for another 25 minutes. The flow rate was kept constant at $0.425 \mathrm{ml} \cdot \mathrm{min}^{-1}$, and $1 \mu \mathrm{mol} / \mathrm{L}$ serine and $2.5 \mathrm{mmol} / \mathrm{L}$ ammonium acetate were used in all solvents as additives.

Mass spectrometry of lipids was performed using electrospray ionisation on a 4000 QTRAP system (Applied Biosystems, Nieuwerkerk aan de IJssel, The Netherlands). Source temperature was set to $450^{\circ} \mathrm{C}$, and nitrogen was used as curtain gas. LPA was measured in negative mode, the optimal ionization energy, declustering potential, and collision energy were empirically determined at $-4500 \mathrm{~V},-110 \mathrm{~V}$, and $-50 \mathrm{~V}$, respectively. Lysophosphatidylcholine (LPC) was measured in positive mode, and the optimal ionization energy, declustering potential, and collision energy were set at $5000 \mathrm{~V}, 110 \mathrm{~V}$, and $45 \mathrm{~V}$, respectively. Both molecular species were measured in multiple reaction monitoring mode, monitor- ing for 34 head group specific mass transitions with a total dwell time of $20 \mathrm{msec} \cdot$ transition $^{-1}$.

\section{RNA Isolation}

Two to three carotid artery segments carrying the plaque from $0,2,4,6$, or 8 weeks after collar placement were pooled for each sample and homogenized by grounding in liquid nitrogen with a pestle. Total RNA was extracted from the tissue homogenates using Trizol reagent according to manufacturer's instructions (Invitrogen, Breda, The Netherlands). RNA was reverse transcribed by $\mathrm{M}$ MuLV reverse transcriptase (RevertAid, MBI Fermentas, Leon-Roth) and used for quantitative analysis of gene expression with an ABI PRISM 7700 Taqman apparatus (Applied Biosystems, Foster City, CA) as described previously, ${ }^{29}$ with murine hypoxanthine phosphoribosyltransferase (HPRT) and cyclophilin A as standard housekeeping genes (Table 1).

\section{Immunohistochemistry}

For immunofluorescence, sections were blocked in $0.1 \%$ Triton-X100 and 2\% goat normal serum for 4 hours, and incubated overnight at $4^{\circ} \mathrm{C}$ with rabbit polyclonal antibodies against CPLA 2 (1:100, Santa Cruz Biotechnology, Santa Cruz, CA) or iPLA 2 (1:500, Cayman Chemical, Ann Arbor, $\mathrm{MI}$ ) together with rat monoclonal antibody against MOMA-2 (1:50, Serotec Inc, Toronto, ON), rat anti-CD31 (1:100, Acris Antibodies GmbH, Hiddenhausen, Germany) or mouse anti SMA-Cy3 conjugated (1:500, Sigma-Aldrich, St Louis, USA). After washes in PBS, sections were incubated for 1 hour at room temperature with a biotinylated goat anti-rabbit secondary antibody (1:500, Jackson ImmunoResearch Laboratories, West Grove, PA) and for MOMA-2 and CD31 slides combined with a 


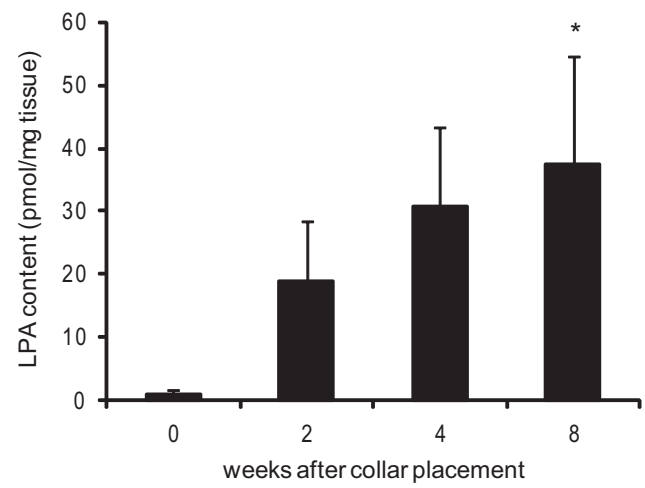

Figure 1. LPA accumulation in carotid artery plaques. LPA quantification in lipid extracts of carotid artery lesions from $\mathrm{LDLr}^{-/}$mice shows that already at two weeks after collar placement, LPA starts accumulating in the vessel wall and continues during plaque development. ${ }^{*} P<0.05$.

goat anti-rat rhodamine-conjugated secondary antibody (1:100, Jackson ImmunoResearch Laboratories), followed by 1-hour incubation with fluorescein-conjugated streptavidin (1:500, Molecular Probes, Eugene, OR). Following several washes with PBS, coverslips were mounted on the sections with DAPI containing mounting medium (Vector Laboratories Inc, Burlingame, CA).

\section{Statistical Analysis}

Data are expressed as mean \pm SEM. Comparison of lesion development-related changes between groups was done by analysis of variance in case of normal distributed values followed by Dunnet posthoc testing or, in case of a non-Gaussian distribution, by Kruskal-Wallis test with Dunn posthoc testing. To determine significance of the relative mRNA expression levels, statistical analysis was performed on $\Delta$ Ct values. A level of $P<0.05$ was considered significant.

\section{Results}

\section{LPA Quantification}

To accelerate atherosclerotic lesion formation, slightly constrictive perivascular collars were placed at the common carotid artery of male Western-type diet-fed $\mathrm{LDLr}^{-1-}$ mice. At 0 to 8 weeks after collar placement, carotid artery segments, proximal to the collar, where plaques will or had developed, were isolated, and entrapped lipids, extracted from these atherosclerotic vessel segments, were analyzed. Intact carotid artery segments contained very little, if any, LPA (0.95 \pm 0.95 $\mathrm{pmol} / \mathrm{mg}$ tissue). LPA levels in advanced lesions were found to increase during atherogenesis via $19 \pm 9$ and $31 \pm 13$ (at 2 and 4 weeks, respectively) to $38 \pm 17$ $\mathrm{pmol} / \mathrm{mg}$ tissue in advanced lesions at 8 weeks after collar placement $(P<0.05$, Figure 1$)$. These data indicate that LPA is abundantly present in mouse atherosclerotic lesions but not in intact arteries.

Moreover, the LPA content of advanced mouse plaques was essentially similar to that observed in human atherosclerotic tissue specimens from high-grade stenotic carotid arteries, ${ }^{5,6}$ rendering it legitimate to use this animal model for further studies on the enzymatic regulation of LPA homeostasis in plaques.

\section{Quantitative LC-MS Analysis of LPA Molecular Species in Mouse Atherosclerotic Plaques}

Rother et al have shown that the platelet-activating effect of the lipid-rich core of atherosclerotic plaques is determined not only by the total amount of LPA but also by the alkyl-acyl ratio and the actual chemical composition of LPA. ${ }^{6}$ Therefore, we set out to map the LPA species present in mouse atherosclerotic plaques by liquid chromatography-mass spectrometry (LC-MS) analysis. In keeping with the enzymatic LPA assay, LC-MS analyses showed the progressive accumulation of multiple LPA species during atherosclerotic lesion development, some of which (e.g., 18:2 LPA, 20:2 LPA [ $P<0.05]$, 20:3 LPA, and 22:4 LPA [ $P<0.05]$ ) known to have potent plateletactivating capacity (Figure 2, A-J). In advanced lesions (8 weeks after collar placement) the major LPA species were 16:0 LPA and 18:1 LPA, contributing 55\% and 21\% of total LPA, respectively. 18:1 LPA, surprisingly, showed a twofold decrease rather than increase during lesion development. However, the relative amounts of the foremost thrombogenic species 18:2 LPA, 20:3 LPA, and $22: 4$ LPA increased from less than $0.2 \%$ in the normal arteries to $6.5 \%, 9.1 \%$, and $4.2 \%$, respectively, in advanced atherosclerotic lesions, implying that this LPA pool may, despite its low abundance, still contribute significantly to the platelet-activating potential of the lipidrich core. Interestingly, preceding the LPA accumulation, already at 4 weeks after lesion initiation, we found a remarkable accumulation of multiple LPC species, which have been attributed a proinflammatory role in atherosclerosis (Figure 3, A-J). ${ }^{30}$ In addition to LPC, also phosphatidylcholine (PC), which is a major component of cell membranes, was increased at 4 weeks of atherosclerotic lesion development (Figure 3, K and L), possibly reflecting an increased cellularity in the plaque at that stage.

\section{Expression Profiling}

In the next step, we investigated whether the increased LPA accumulation correlates with altered plaque expression of important enzymes in LPA homeostasis and LPA effector proteins.

Induction of atherosclerotic lesion development is reflected by an increase in CD68 expression, which peaks at 4 weeks after collar placement indicating an influx of macrophages (Figure 4A). The CD68 expression pattern concurs with the increase in phosphatidylcholine measured by LC-MS. No changes were seen for phospholipase D (PLD) $)_{1}$ and $\mathrm{PLD}_{2}$, which hydrolyze glycerophospholipids under formation of phosphatidic acid (PA, data not shown). Interestingly, cytosolic phospholipase $A_{2}$ group IVA (CPLA $\left.A_{2} I V A\right)$ and calcium-independent phospholipase $A_{2}$ group VIA (iPLA $A_{2}$ VIA), potentially involved in the intracellular conversion of PA into LPA, were both 
A

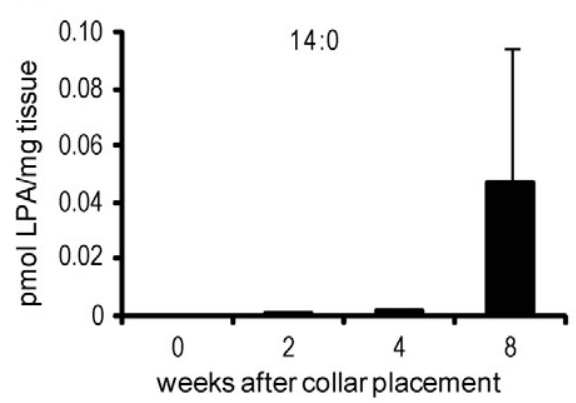

D

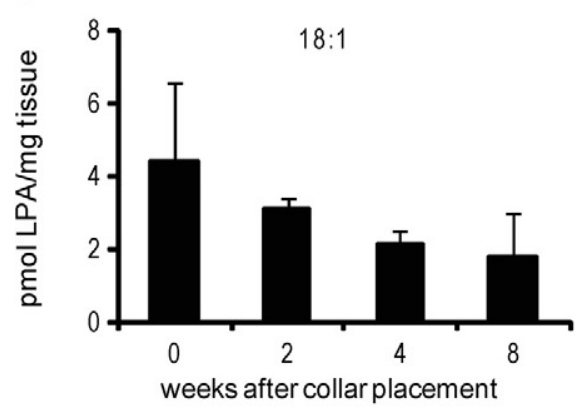

G

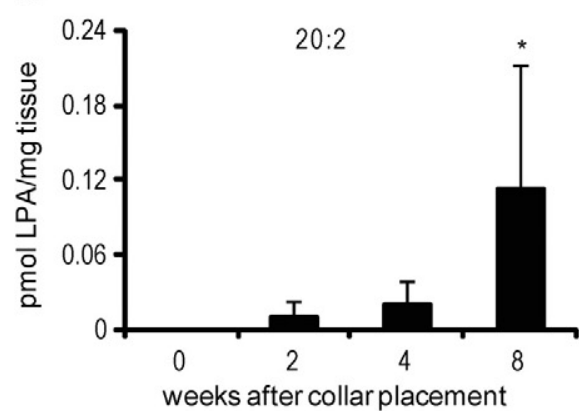

J

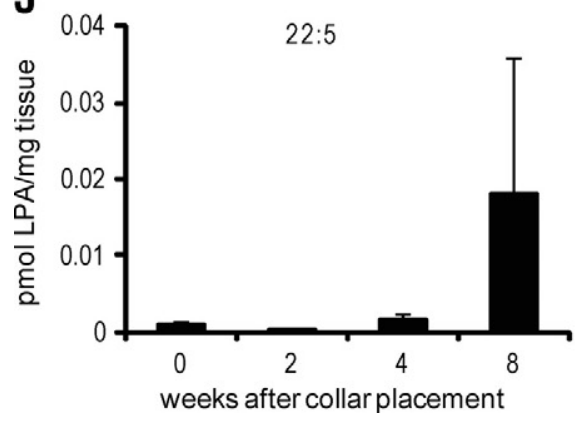

B

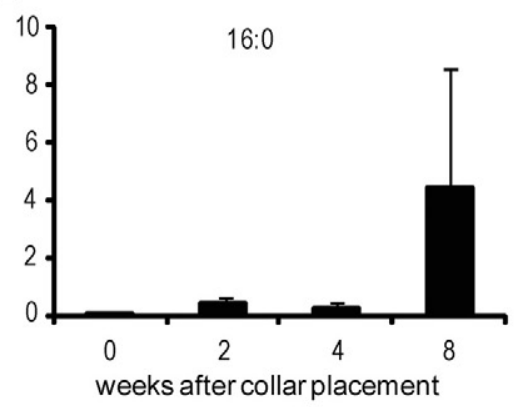

E

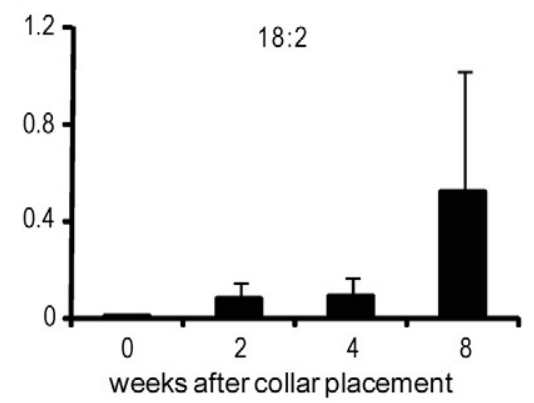

H

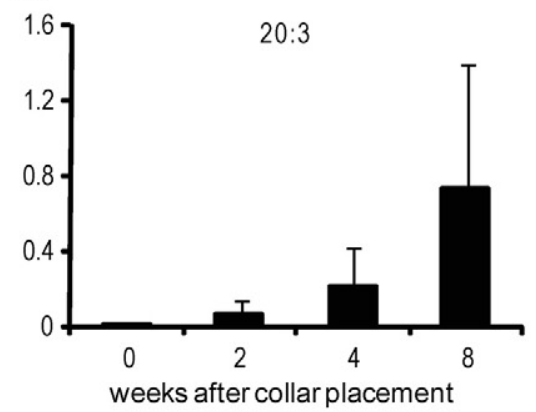

C

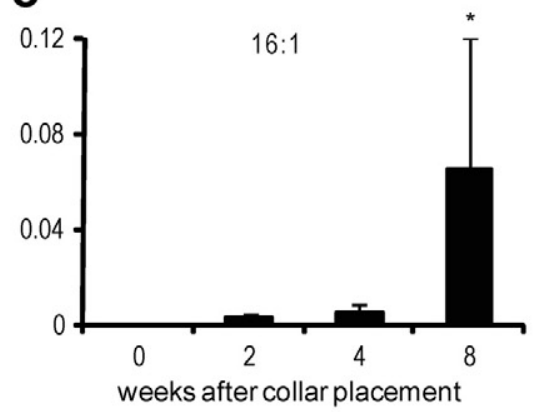

$\mathbf{F}$

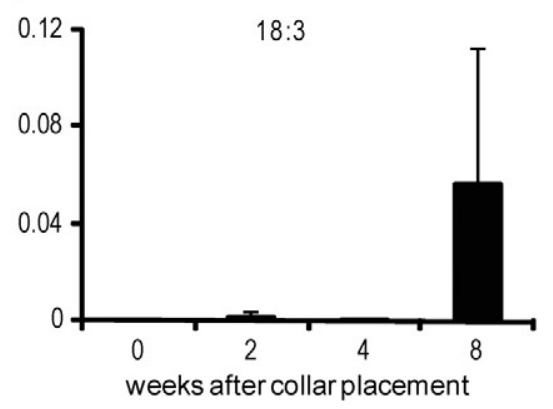

I

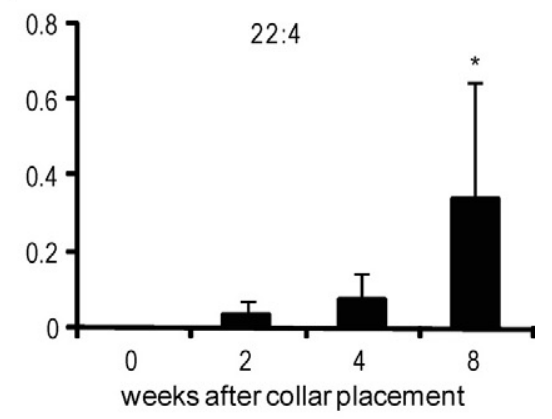

Figure 2. Accumulation of LPA species during collar-aided plaque development in carotid arteries of LDLr ${ }^{-/-}$mice. MS-analysis shows accumulation of highly unsaturated long-chain LPA species in plaque lipid extracts. A: 14:0; B: 16:0; C: 16:1; D: 18:1; E: 18:2; F: 18:3; G: 20:2; H: 20:3; I: 22:4; J: 22:5. ${ }^{*} P<0.05$.

upregulated by up to twofold during atherogenesis $(P<$ 0.01 and NS, respectively; Figure 4, B and C). Gene expression of LPAAT $\alpha$, which converts LPA into PA, progressively decreased by up to $75 \%(P<0.05$, Figure 4D). The expression of lipid phosphate phosphatase 1, which converts LPA to monoacylglycerol, did not change (MAG, Figure 4E), whereas that of lysophosphatidic acid phosphatase, a regulator of mitochondrial lipid metabolism by hydrolyzing LPA, was twofold down-regulated during lesion progression ( $P<0.01$, data not shown).
Because LPA signal transduction might also be altered during atherogenesis, we studied the expression of various $L P A$ receptors. $L_{P A}$ and $L P A_{2}$ expression were altered during atherogenesis (50\% reduction, $P<0.05$, and sevenfold increase, $P<0.01$, respectively, Figure $4 \mathrm{~F}$ ), whereas that of $\mathrm{LPA}_{3}$ and GPR23 did not show any significant changes (Figure 4F and data not shown). PPAR $\gamma$, a nuclear transcription factor known to be activated by LPA, and its effector CD36 showed a 14- and 13-fold decrease in expression, respectively ( $P<0.01$, Figure $4, \mathrm{G}$ and $\mathrm{H}$ ). 
A

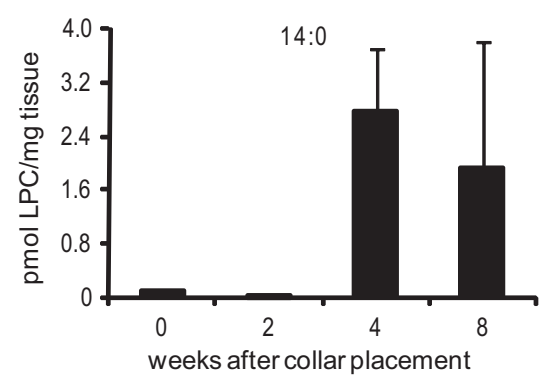

D
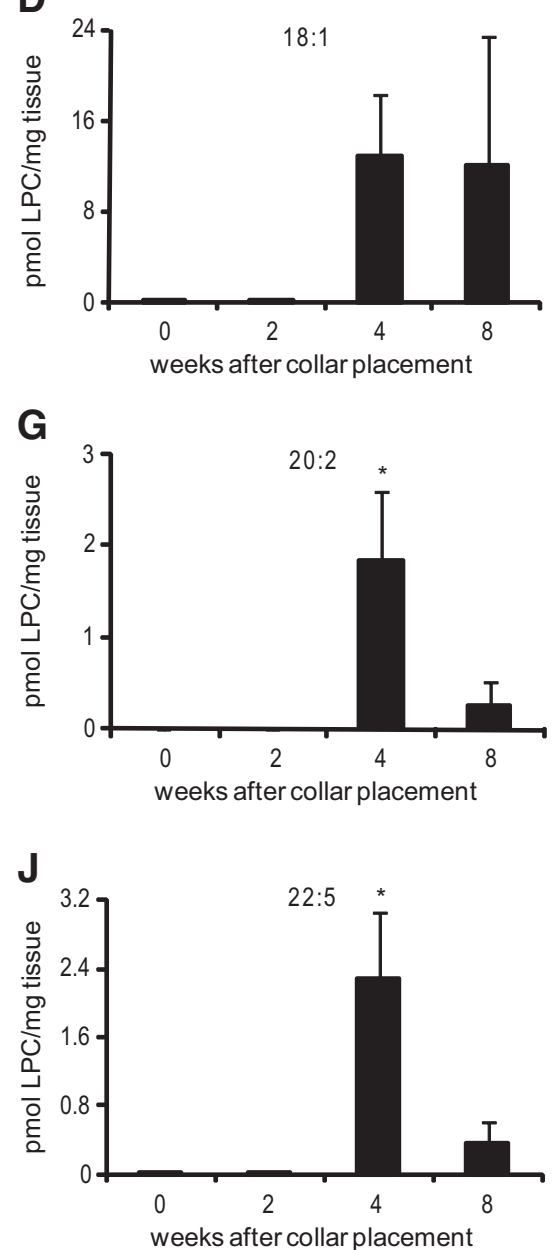

B

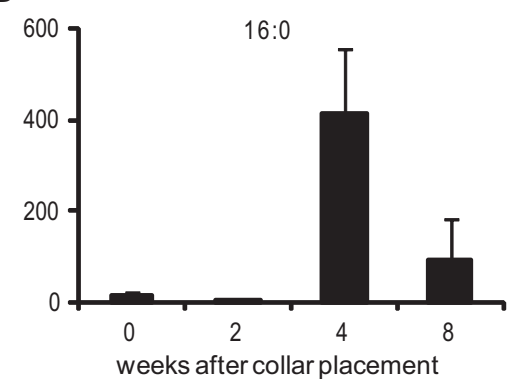

E

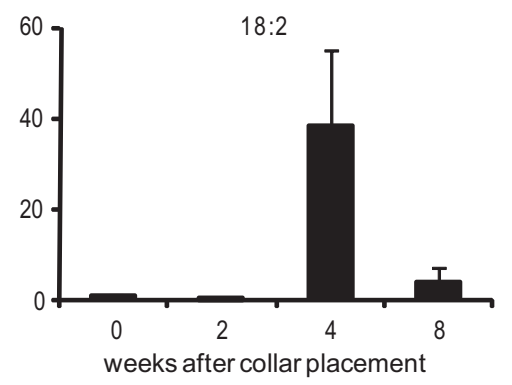

H
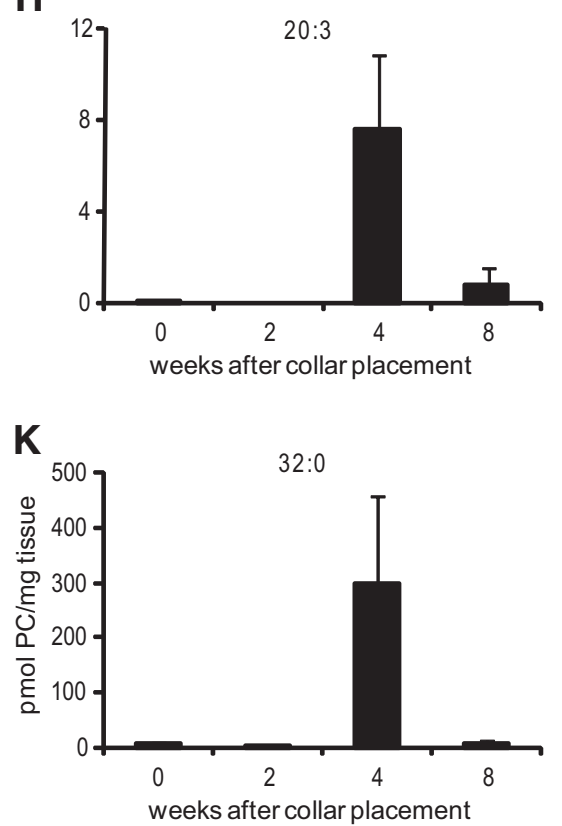

C

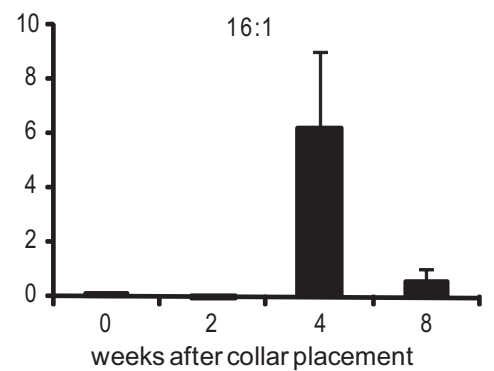

$\mathbf{F}$

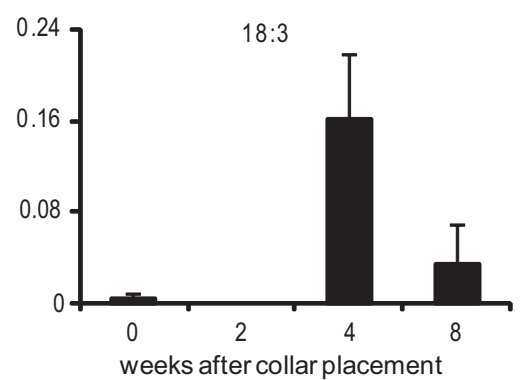

I

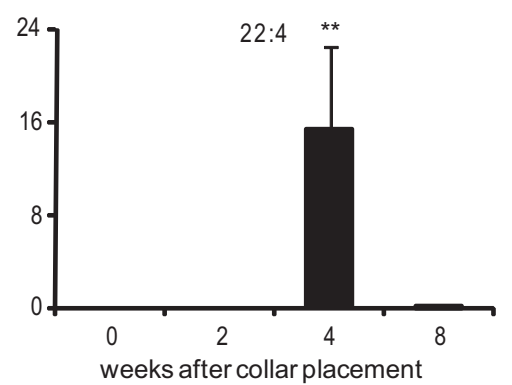

$\mathbf{L}$

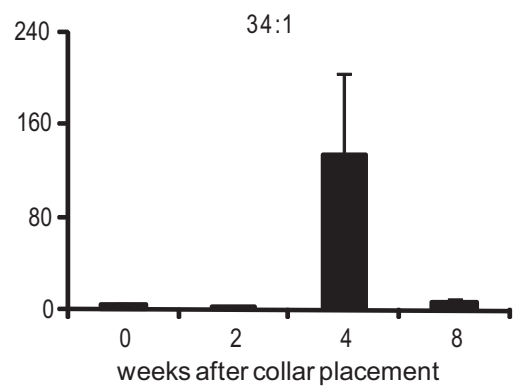

Figure 3. Accumulation of LPC and PC species during collar-aided plaque development in carotid arteries of LDLr ${ }^{-/-}$mice. MS-analysis shows strong accumulation of multiple LPC species in plaque lipid extracts. A: 14:0; B: 16:0; C: 16:1; D: 18:1; E: 18:2; F: 18:3; G: 20:2; H: 20:3; I: 22:4; J: 22:5; K: 32:0; L: 34:1. ${ }^{*} P<0.05,{ }^{* * *} P<0.01$.

Intracellular LPA is believed to be transported in part by fatty acid binding proteins (FABPs), which belong to a family of intracellular lipid binding proteins, and some of these FABPs, including liver FABP, have already been shown to be able of binding and sequestering LPA in mitochondria at micromolar concentrations. Although the exact role of FABPs in LPA transport from the endoplasmatic reticulum and the mitochondria to the cytoplasm remains to be determined, the net activity of LPA might be related to the expression pattern of FABPs. Therefore, expression of FABPs was measured. FABP1, -2, and
-5, also known as L(liver)-, I(intestine)-, and $\mathrm{E}$ (epidermal)-FABPs, were upregulated over time (Figure 5, A, B, and E). However, 8 weeks after collar placement the expression of FABP1 and -2 displayed a sharp decline, which concurred with that of the vascular smooth muscle cell marker $\alpha$-actin and nonmuscle myosin heavy chain (data not shown). Expression of FABP3 and -4 , the $\mathrm{H}$ (heart)- and $\mathrm{A}$ (adipocyte)-FABP, respectively, was almost ablated during atherogenesis ( $-96 \%$ compared with non-atherosclerotic tissue; $P<0.01$, Figure 5, C and D). 
A

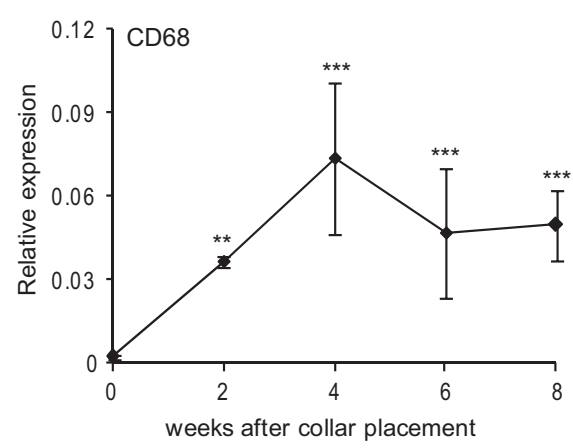

D

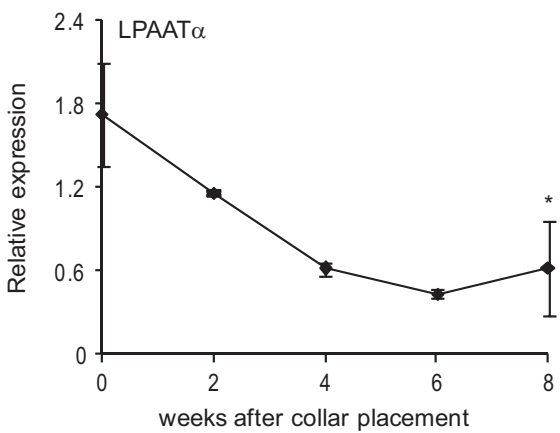

G

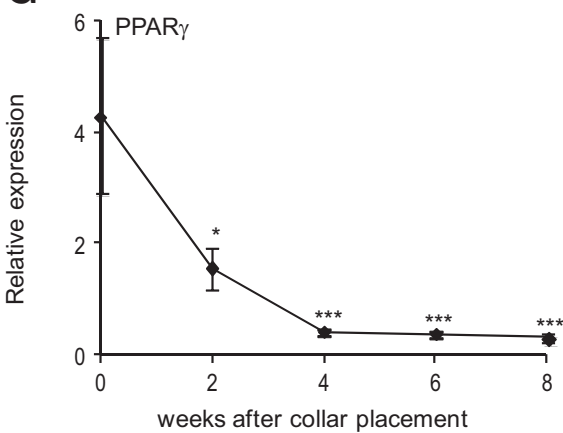

B

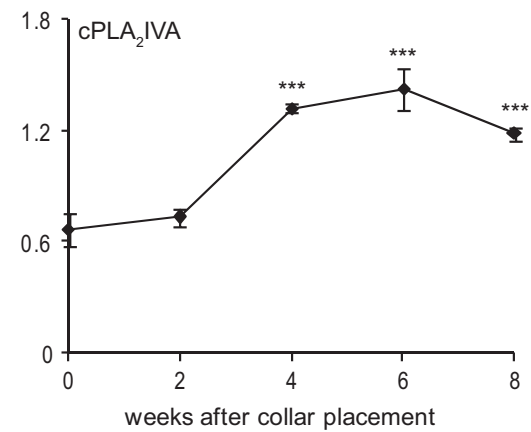

E

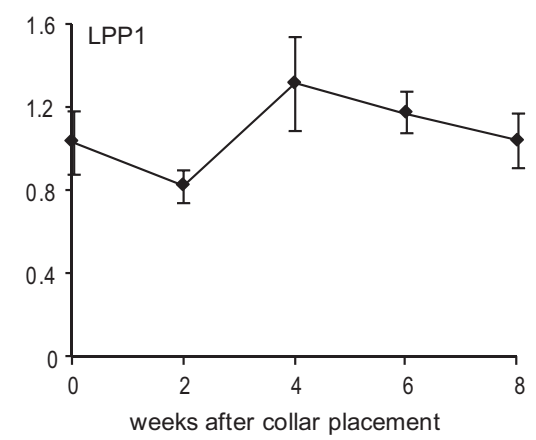

H

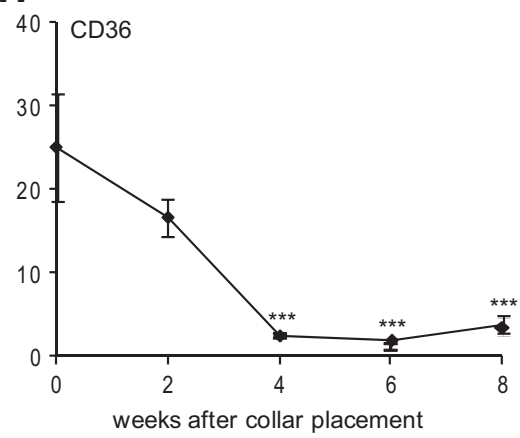

C

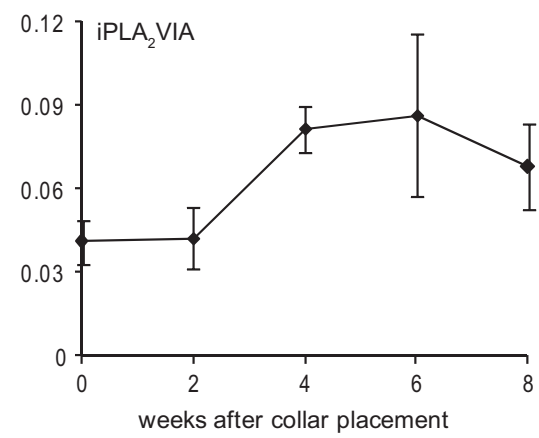

$\mathbf{F}$

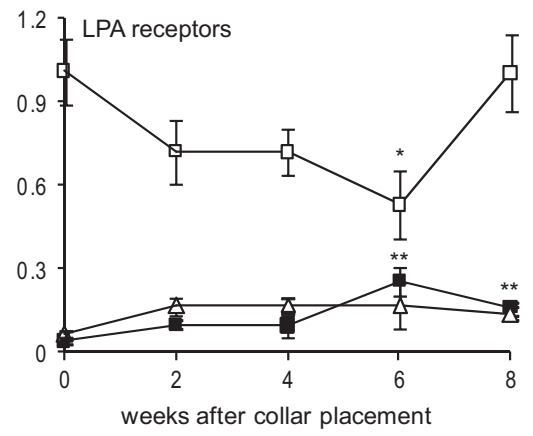

Figure 4. Gene expression profile of LPA-metabolizing enzymes and LPA receptors. A: Induction of atherosclerotic lesion development is reflected by an increase in CD68 expression, indicating an influx of macrophages. B: CPLA IVA, involved in PA conversion to LPA, is highly significantly upregulated in atherosclerotic lesions compared with nonatherosclerotic artery tissue. C: iPLA 2 VIA is also twofold upregulated during lesion progression. D: The gene expression pattern of LPAAT $\alpha$, which converts LPA into PA, revealed a down-regulation during atherogenesis. E: No changes were seen on the gene expression of LPP1, which converts

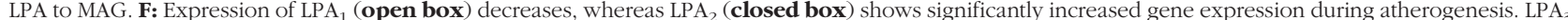
does not show any significant changes (open triangle). G: PPAR $\gamma$, the nuclear receptor known to be activated by LPA, and its effector CD36 (H) both illustrate a 13 -fold reduction in relative expression. ${ }^{*} P<0.05,{ }^{* *} P<0.01,{ }^{* * * *} P<0.001$.

\section{Immunofluorescence}

Verification of increased expression at the protein level was performed for both CPLA ${ }_{2} I V A$ and iPLA ${ }_{2} V I A$. Increased expression of $\mathrm{CPLA} \mathrm{A}_{2}$ and $\mathrm{iPLA}_{2}$ was observed by immunofluorescence in advanced atherosclerotic lesions (Figure 6, A, D, and G, and Figure 7, A, D, and $G$. Expression was localized both in the central atheroma and in the lesion cap suggesting that both enzymes can be produced by multiple plaque cell types. In fact, double-immunofluorescence labeling indicated that $\mathrm{CPLA}_{2}-$ and $\mathrm{iPLA}_{2}$-expressing cells in these plaques can be CD31-positive endothelial cells, smooth muscle actin (SMA)-positive vascular smooth muscle cells, and MOMA-2-positive macrophages
(Figure 6, B, C, E, F, H, and I, and Figure 7, B, C, E, F, $\mathrm{H}$, and I).

\section{Discussion}

Acute coronary syndromes as unstable angina and myocardial infarction are thought to be caused by erosion or rupture of atherosclerotic plaques and superimposed thrombosis. Rupture-prone plaques are characterized by a large eccentric lipid core underlying a thin fibrous cap. ${ }^{1-4}$ LPA, a highly thrombogenic lipid plaque constituent, was previously shown to accumulate in the lipid core of human atherosclerotic lesions. ${ }^{5,6}$ We show here that LPA progressively accumulates in mouse atheroscle- 
A

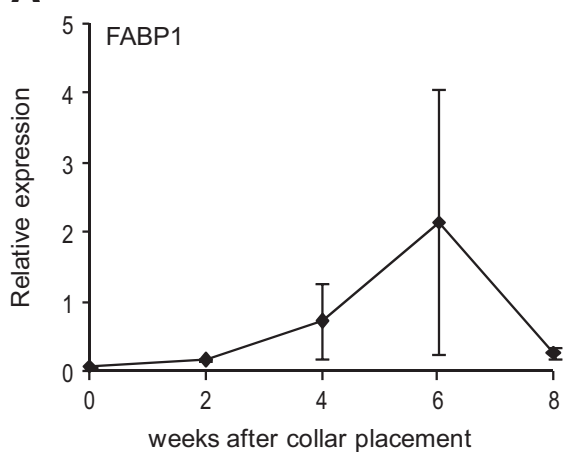

D

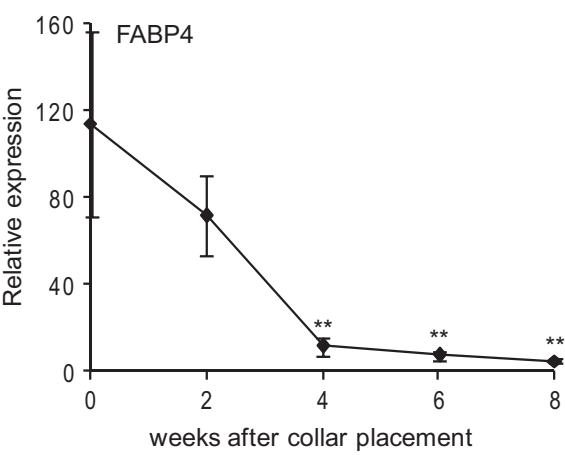

B

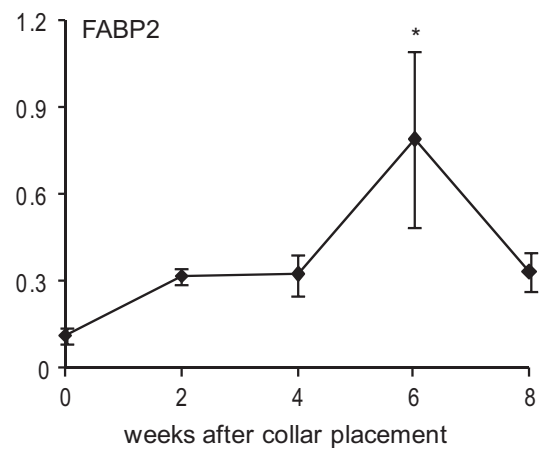

E

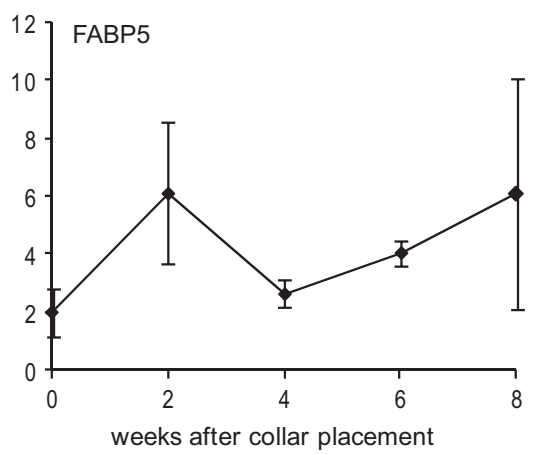

C

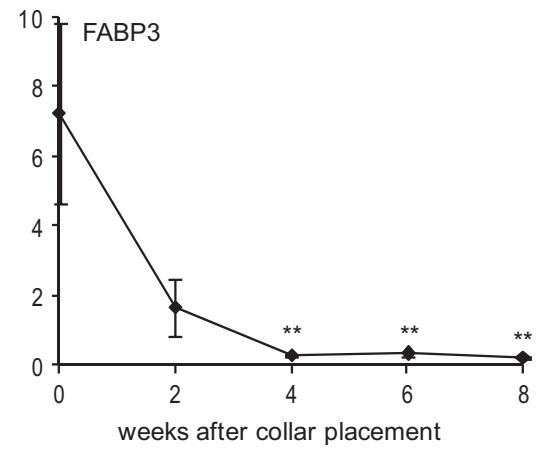

Figure 5. Expression pattern of the FABPs in atherosclerotic plaques. A: The expression profile of FABP1 did not change significantly during atherogenesis. B: The expression profile of FABP2 reveals a significant increase in relative expression up to week 6, after which a sharp decrease in expression is observed. $\mathbf{C}$ and $\mathbf{D}$ : Gene expression of FABP3 and -4 is significantly down-regulated during atherogenesis up to $95 \%$ in advanced plaques compared with week 0 (nonatherosclerotic tissue). E: The expression profile of FABP5 did not change significantly during atherogenesis ${ }^{*} P<0.05,{ }^{* * *} P<0.01$ rotic lesions as well, at concentrations that, particularly at 8 weeks after collar placement when advanced atherosclerotic lesions have developed, are essentially similar to those observed in human atherosclerotic tissue specimens from high-grade stenotic carotid arteries. ${ }^{5,6}$ Furthermore, we demonstrate accumulation of highly unsaturated long-chain acyl-LPA species, deemed to have particularly high platelet-activating capacity. Finally, this study is the first to report altered LPA metabolism within the plaque, pointing to increased LPA production during plaque progression.

As shown by Rother et al, the platelet-activating effect of the lipid-rich core of atherosclerotic plaques is determined not only by the total amount of LPA but also by the alkyl-acyl ratio and the chemical composition of LPA species in the plaque. ${ }^{6}$ Our study confirms this finding, in that several LPA species, among which the highly unsaturated long-chain acyl-LPA 18:2 LPA, 20:3 LPA, and 22:4 LPA are progressively accumulating in the atherosclerotic plaque during disease progression in mice as well. Remarkably, we also observed accumulation of LPC, which has been implicated in modulation of platelet function as well. ${ }^{20}$ Whereas at low concentrations LPC $(<30$ $\mu \mathrm{mol} / \mathrm{L})$ does not influence platelet activation, higher concentrations of LPC (100 $\mu \mathrm{mol} / \mathrm{L})$ or LPC-containing oxLDL caused a transient inhibitory effect and a subsequent potentiation of platelet activity. ${ }^{20}$ These effects were attributed to the amphiphilic nature of LPC, intercalating into the platelet membrane, rather than binding to specific receptors. ${ }^{20}$ Conceivably LPC could, on plaque rupture, initially act as inhibitor to evolve into an inducer of platelet aggregation. In this study, the observed LPC accumulation preceded that of LPA, suggesting that LPC may serve as a major source of intraplaque LPA production. LPC to LPA conversion requires lysophospholipase $D$ (LysoPLD, Autotaxin) enzyme activity ${ }^{31}$ within the atherosclerotic lesion. Indeed, increased serum LPC concentrations, as observed in rabbits on high-fat diet feeding, were accompanied by increased LysoPLD activity and LPA levels in serum, underpinning a critical role of LysoPLD in LPA homeostasis and potentially in atherosclerotic lesion development. ${ }^{32}$ As lysoPLD is a secreted enzyme with prominent expression in blood, the plaque expression pattern during atherogenesis may not be very reflective of plaque LPA homeostasis.

Collectively our data show that LPA progressively accumulates in intimal tissue during atherosclerotic lesion progression. The question remains to what extent plaque LPA originates from extravasated subendothelially retained LDL or is synthesized in situ. Efforts to address this issue, by in situ monitoring of uptake of $\left[{ }^{3} \mathrm{H}-\right]-L P A$ labeled LDL by plaques, failed because of immediate and almost complete exchange of labeled LPA to the circulating pool of unlabeled LPA. In addition, we were unable to track LPA synthesis by mouse plaque lysates (even if multiple vessel sections were pooled) after metabolic labeling with deuterated phosphatidic acid, despite the state-ofthe-art analysis on the 4000 QTRAP. We conclude that at this point in time, with the currently available methods, it is impossible to accurately pinpoint the actual source of in vivo LPA accumulation. However, considerable build-up of LPA was observed in the vessel wall already 

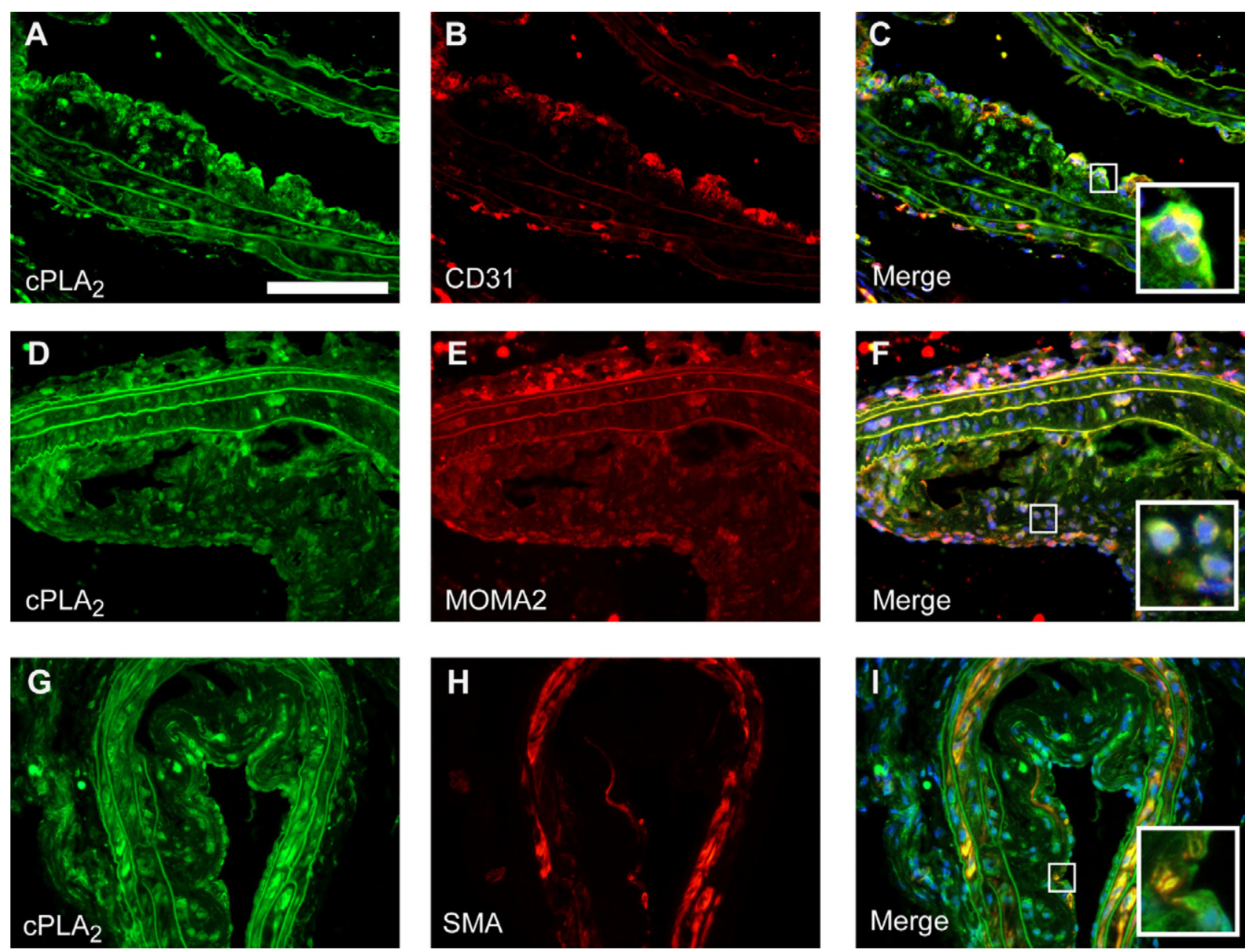

Figure 6. Immunohistochemically stained cryosections of advanced atherosclerotic lesions. cPLA, $(\mathbf{A}, \mathbf{D}$, and $\mathbf{G}$, scale bar $=100 \mu \mathrm{m})$ colocalizes with the endothelial specific marker CD31 (B; merge $\mathbf{C}$ ), the monocyte/macrophage specific marker MOMA-2 (E; merge F), and the smooth muscle specific marker SM-actin (SMA, H; merge I). The insets show a high-power view of plaque foci with double-positive cells.

at 2 weeks after collar placement, when initial lesions start to develop. Conceivably, LDL-derived LPA is the main contributor at this stage. At later stages, cellular metabolism may become more important as an LPA source (Figure 8).

Therefore, we have mapped the expression of key genes in LPA synthesis and breakdown at different stages of lesion development. Our expression data point toward an increased LPA synthesis in atherosclerotic plaques. CPLA $A_{2} I V A$ and $i P L A_{2} V I A$, the two major intracellular $P L A_{2}$ enzymes in humans, ${ }^{33}$ were upregulated, which could indirectly translate into increased LPA production. Immunohistochemical analysis of plaque cryosections confirmed the markedly increased expression of both $C P L A_{2} V I A$ as ${ }_{i P L} A_{2} \mathrm{VIA}$ in advanced atherosclerotic lesions. Although the relative contribution of these PLA family members to the whole body LPA production remains controversial, ${ }^{34}$ our findings support such a role in the context of atherosclerosis. Indications for a strong involvement of these PLA family members in LPA production have been furnished by Tang et al, among others, who reported effective and preferred conversion of 1,2-dipalmitoyl phosphatidic acid into lysophosphatidic acid by iPLA $\mathrm{VIA}^{35}$ In our study we show an increased presence of palmitoyl (16:1) LPA in advanced atherosclerotic lesions, supportive of an important role for iPLA $\mathrm{A}_{2} \mathrm{VIA}$ in LPA accumulation during lesion development. In addition, both $C P L A_{2}$ VIA as $i_{2} A_{2}$ VIA have been implicated in LPA production by peritoneal mesothelial cells involved in metastasizing ovarian cancer. ${ }^{36}$ Furthermore, cytosolic PLA $\mathrm{A}_{2}$ is involved in vascular smooth muscle cell and macrophage apoptosis ${ }^{37,38}$ and in the production of proinflammatory prostaglandins via arachidonic acid, pointing to a proatherogenic and plaque destabilizing activity of this enzyme. Finally, in our study we observed down-regulation of the LPA-converting enzyme LPAAT $\alpha{ }^{39}$

Not only was LPA homeostasis perturbed during atherogenesis, LPA signal transduction also seemed to be changed in that LPA 1 was down- and $L P A_{2}$ up-regulated. Selective antagonism of both $\mathrm{LPA}_{1}$ and $\mathrm{LPA}_{3}$ on platelets was shown to quench plaque lipid-induced platelet activation, ${ }^{6}$ suggesting that the observed alterations in LPA receptor expression may well influence the risk of atherothrombosis. Of note, the intracellular LPA receptor PPAR $\gamma$ and its downstream effector CD36 were profoundly downregulated in advanced atherosclerotic plaques. PPAR $\gamma$ ac- 

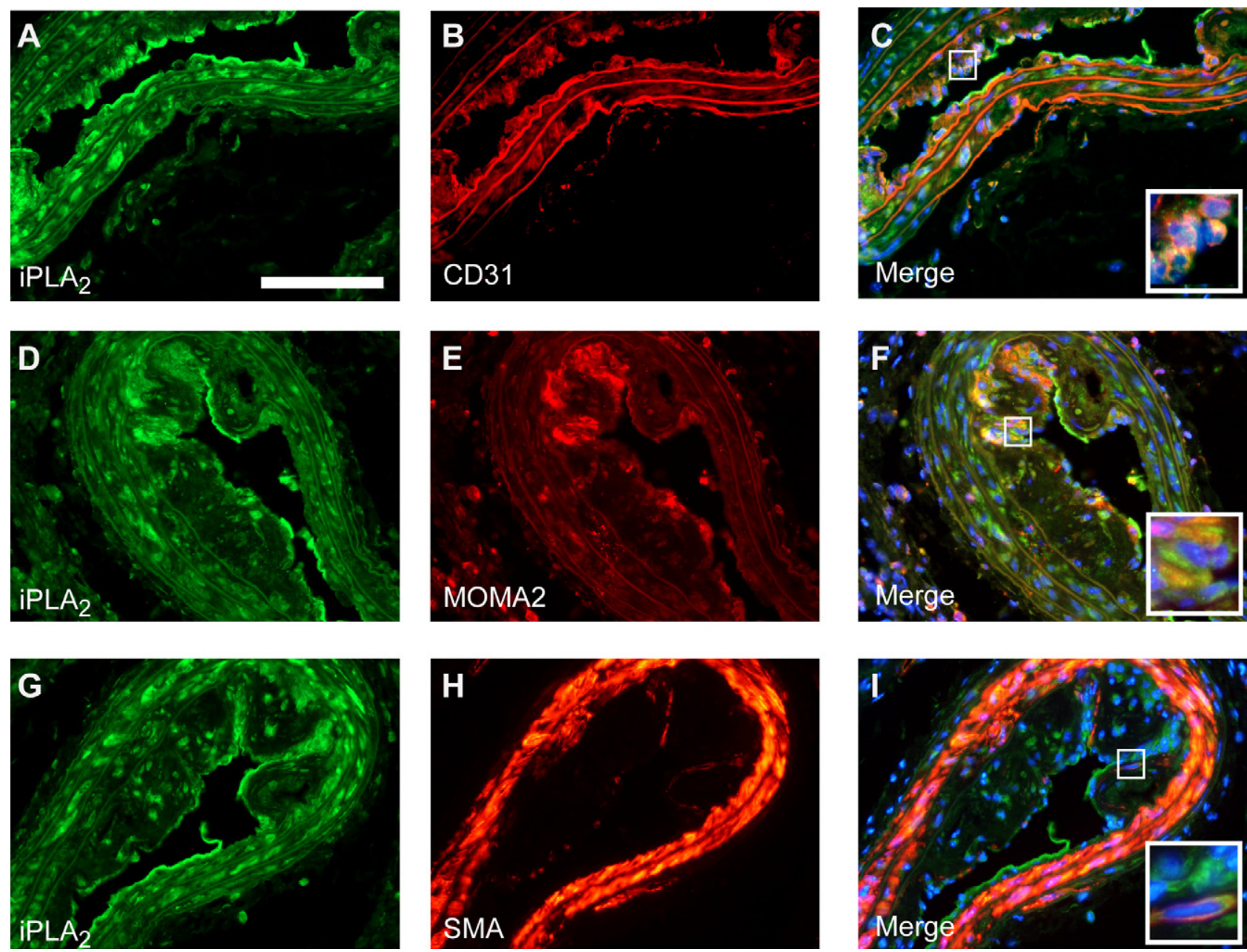

Figure 7. Immunohistochemically stained cryosections of advanced atherosclerotic lesions. iPLA $(\mathbf{A}, \mathbf{D}$, and $\mathbf{G}$, scale bar $=100 \mu \mathrm{m})$ colocalizes with the endothelial specific marker CD31 (B; merge $\mathbf{C}$ ), the monocyte/macrophage specific marker MOMA-2 (E; merge $\mathbf{F}$ ), and the smooth muscle-specific marker SM-actin (SMA, $\mathbf{H}$; merge $\mathbf{I}$ ). The insets show a high-power view of plaque foci with double-positive cells.

tivation has been associated with reduced atherosclerosis and regulates the expression of many genes involved in inflammation and lipid homeostasis, ${ }^{40}$ implying that its down-regulation may act proatherogenic.

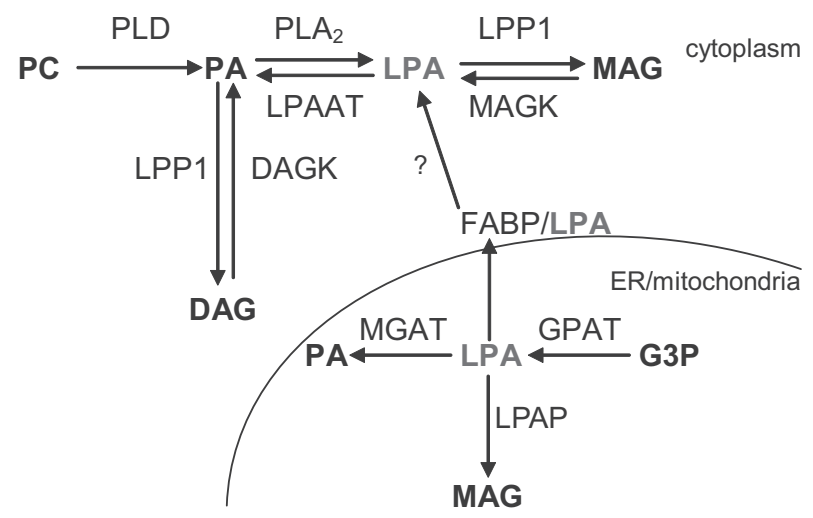

Figure 8. Intracellular pathways of LPA production and degradation. LPA can be produced from either PA or monoacylglycerol (MAG) by PLA 2 and MAGkinase, respectively, whereas it is degraded by LPAAT $\alpha$ and lipid phosphate phosphatase (LPP) 1 . The link between the FABPs and transport of LPA to the cytoplasm has not been proven yet. DAG (K) indicates diacylglycerol (kinase); ER, endoplasmic reticulum; MGAT, monoacylglycerophosphate acyltransferase; GPAT, glycerophosphate acyltransferase; G3P, glycero-3-phosphate.
A third group of critical proteins in LPA homeostasis are the FABPs, which can bind intracellular LPA and have been shown to play a role in atherosclerosis. ${ }^{41}$ Deficiency in the adipocyte-specific FABP4 (aP2) in macrophages attenuated atherosclerosis in hypercholesterolemic mice. ${ }^{42,43}$ Expression analysis revealed a down-regulation of FABP4 during plaque development, suggesting that FABP4 may contribute to the initiation of atherosclerotic lesion development. Recently, Makowski et al described a role for aP2 in macrophage cholesterol trafficking and inflammatory activity. ${ }^{44}$ Our data on cardiomyocyte-specific FABP3 expression during atherogenesis are in keeping with earlier reports in rabbits, ${ }^{45,46}$ showing decreased FABP3 activity in atherosclerotic aortas on high cholesterol feeding. The effect of FABP3 down-regulation on atherogenesis has, however, not yet been elucidated.

In conclusion, LPA progressively accumulates during atherogenesis in mice as well. The observed increased deposition of potent platelet-activating LPA species and proinflammatory LPC species in advanced atherosclerotic lesions indicates that thin cap fibroatheroma are characterized not only by cellular and morphological features but also by a prothrombotic lipid profile. Although we only have verified the temporal expression profiling for 
two critical enzymes in LPA metabolism by immunohistochemistry, the shifted gene expression profiles will likely favor a net accumulation of LPA and altered LPA receptor signal transduction during plaque progression. As such, this study identifies a number of potentially relevant candidate genes for further investigation of their impact on plaque progression on the one and plaque thrombogenicity on the other hand. Furthermore, it suggests that intervention in the LPA metabolism can be an effective new therapeutic entry in the reduction of plaque thrombogenicity.

\section{References}

1. Ross R: Atherosclerosis, an inflammatory disease. N Engl J Med 1999, 340:115-126

2. Libby P: Current concepts of the pathogenesis of the acute coronary syndromes. Circulation 2001, 104:365-372

3. Shah PK: Mechanisms of plaque vulnerability and rupture. J Am Coll Cardiol 2003, 41:15S-22S

4. Falk E: Why do plaques rupture? Circulation 1992, 86:III30-III42

5. Siess W, Zangl KJ, Essler M, Bauer M, Brandl R, Corrinth C, Bittman R, Tigyi G, Aepfelbacher M: Lysophosphatidic acid mediates the rapid activation of platelets and endothelial cells by mildly oxidized low density lipoprotein and accumulates in human atherosclerotic lesions. Proc Natl Acad Sci U S A 1999, 96:6931-6936

6. Rother E, Brandl R, Baker DL, Goyal P, Gebhard H, Tigyi G, Siess W: Subtype-selective antagonists of lysophosphatidic acid receptors inhibit platelet activation triggered by the lipid core of atherosclerotic plaques. Circulation 2003, 108:741-747

7. Siess W, Tigyi G: Thrombogenic and atherogenic activities of lysophosphatidic acid. J Cell Biochem 2004, 92:1086-1094

8. Moolenaar WH: Lysophosphatidic acid, a multifunctional phospholipid messenger. J Biol Chem 1995, 270:12949-12952

9. Moolenaar WH: Lysophosphatidic acid signalling. Curr Opin Cell Biol 1995, 7:203-210

10. Moolenaar WH, Kranenburg O, Postma FR, Zondag GC: Lysophosphatidic acid: g-protein signaling and cellular responses. Curr Opin Cell Biol 1997, 9:168-173

11. Rizza C, Leitinger N, Yue J, Fischer DJ, Wang DA, Shih PT, Lee H, Tigyi G, Berliner JA: Lysophosphatidic acid as a regulator of endothelial/leukocyte interaction. Lab Invest 1999, 79:1227-1235

12. Gennero I, Xuereb JM, Simon MF, Girolami JP, Bascands JL, Chap H, Boneu B, Sie P: Effects of lysophosphatidic acid on proliferation and cytosolic $\mathrm{Ca}++$ of human adult vascular smooth muscle cells in culture. Thromb Res 1999, 94:317-326

13. Natarajan V, Scribner WM, Hart CM, Parthasarathy S: Oxidized low density lipoprotein mediated activation of phospholipase $\mathrm{D}$ in smooth muscle cells: a possible role in cell proliferation and atherogenesis. $J$ Lipid Res 1995, 36:2005-2016

14. Siess W: Athero- and thrombogenic actions of lysophosphatidic acid and sphingosine-1-phosphate. Biochim Biophys Acta 2002, 1582:204-215

15. Goetzl EJ, An S: Diversity of cellular receptors and functions for the lysophospholipid growth factors lysophosphatidic acid and sphingosine 1-phosphate. FASEB J 1998, 12:1589-1598

16. Noguchi K, Ishii S, Shimizu T: Identification of p2y9/GPR23 as a novel $G$ protein-coupled receptor for lysophosphatidic acid, structurally distant from the Edg family. J Biol Chem 2003, 278:25600-25606

17. Kotarsky K, Boketoft A, Bristulf J, Nilsson NE, Norberg A, Hansson S, Owman C, Sillard R, Leeb-Lundberg LM, Olde B: Lysophosphatidic Acid Binds to and Activates GPR92, a G Protein-Coupled Receptor Highly Expressed in Gastrointestinal Lymphocytes. J Pharmaco Exp Ther 2006, 318:619-628

18. Gobeil F Jr., Bernier SG, Vazquez-Tello A, Brault S, Beauchamp MH, Quiniou C, Marrache AM, Checchin D, Sennlaub F, Hou X, Nader M, Bkaily G, Ribeiro-da-Silva A, Goetzl EJ, Chemtob S: Modulation of Pro-inflammatory Gene Expression by Nuclear Lysophosphatidic Acid Receptor Type-1. J Biol Chem 2003, 278:37875-38883

19. Zhang C, Baker DL, Yasuda S, Makarova N, Balazs L, Johnson LR,
Marathe GK, Mclntyre TM, Xu Y, Prestwich GD, Byun HS, Bittman R, Tigyi G: Lysophosphatidic acid induces neointima formation through PPARgamma activation. J Exp Med 2004, 199:763-774

20. Siess W: Platelet interaction with bioactive lipids formed by mild oxidation of low-density lipoprotein. Pathophysiol Haemost Thromb 2006, 35:292-304

21. Gustafsson $M$, Levin $M$, Skålén $K$, Perman J, Fridén V, Jirholt $P$, Olofsson SO, Fazio S, Linton MF, Semenkovich CF, Olivecrona G, Borén J: Retention of low-density lipoprotein in atherosclerotic lesions of the mouse: evidence for a role of lipoprotein lipase. Circ Res 2007 101:777-783

22. Guyton JR: Phospholipid hydrolytic enzymes in a 'cesspool' of arterial intimal lipoproteins: a mechanism for atherogenic lipid accumulation. Arterioscler Thromb Vasc Biol 2001, 21:884-886

23. von der Thüsen JH, van Berkel TJC, Biessen EAL: Induction of rapid atherogenesis by perivascular carotid collar placement in apolipoprotein E-deficient and low-density lipoprotein receptor-deficient mice. Circulation 2001, 103:1164-1170

24. Bligh EG, Dyer WJ: A rapid method of total lipid extraction and purification. Can J Med Sci 1959, 37:911-917

25. Bierve KS, Daae LN, Bremer J: The selective loss of lysophospholipids in some commonly used lipid-extraction procedures. Anal Biochem 1974, 58:238-245

26. Bremer J: Carnitine in intermediary metabolism. The biosynthesis of palmitylcarnitine by cell subfraction J Biol Chem 1963, 238:2774-2779

27. Saulnier-Blache JS, Girard A, Simon MF, Lafontan M, Valet P: A simple and highly sensitive radioenzymatic assay for lysophosphatidic acid quantification. J Lipid Res 2000, 41:1947-1951

28. Retra K, Bleijerveld OB, Van Gestel RA, Tielens AGM, Van Hellemond JJ, Brouwers JF: A simple and universal method for the separation and identification of phospholipid molecular species. Rapid Communications in Mass Spectrometry 2008, 22:1853-1862

29. 't Hoen PA, Van der Lans CA, Van Eck M, Bijsterbosch MK, Van Berkel TJ, Twisk J: Aorta of ApoE-deficient mice responds to atherogenic stimuli by a prelesional increase and subsequent decrease in the expression of antioxidant enzymes. Circ Res 2003, 93:262-269

30. Olofsson KE, Andersson L, Nilsson J, Björkbacka H: Nanomolar concentrations of lysophosphatidylcholine recruit monocytes and induce pro-inflammatory cytokine production in macrophages. Biochem Biophys Res Commun 2008, 370:348-352

31. Aoki J, Taira A, Takanezawa Y, Kishi Y, Hama K, Kishimoto T, Mizuno K, Saku K, Taguchi R, Arai H: Serum lysophosphatidic acid is produced through diverse phospholipase pathways. J Biol Chem 2002, 277:48737-48744

32. Tokumura A, Kanaya Y, Kitahara M, Miyake M, Yoshioka Y, Fukuzawa $\mathrm{K}$ : Increased formation of lysophosphatidic acids by lysophospholipase D in serum of hypercholesterolemic rabbits. J Lipid Res 2002, 43:307-315

33. Pickard RT, Strifler BA, Kramer RM, Sharp JD: Molecular cloning of two new human paralogs of $85-\mathrm{kDa}$ cytosolic phospholipase A2. J Biol Chem 1999, 274:8823-8831

34. Pages C, Simon MF, Valet P, Saulnier-Blache JS: Lysophosphatidic acid synthesis and release. Prostaglandins Other Lipid Mediat 2001, 64:1-10

35. Tang J, Kriz RW, Wolfman N, Shaffer M, Seehra J, Jones SS: A novel cytosolic calcium-independent phospholipase $\mathrm{A}_{2}$ contains eight ankyrin motifs. J Biol Chem 1997, 272:8567-8575

36. Ren J, Xiao Y, Singh LS, Zhao X, Zhao Z, Feng L, Rose TM, Prestwich GD, Xu Y: Lysophosphatidic acid is constitutively produced by human peritoneal mesothelial cells and enhances adhesion, migration, and invasion of ovarian cancer cells. Cancer Res 2006, 66:3001-3014

37. Pilane CM, LaBelle EF: Arachidonic acid release by CPLA2 may be causally related to NO-induced apoptosis in vascular smooth muscle cells. J Cell Physiol 2002, 191:191-197

38. Panini SR, Yang L, Rusinol AE, Sinensky MS, Bonventre JV, Leslie CC: Arachidonate metabolism and the signaling pathway of induction of apoptosis by oxidized LDL/oxysterol. J Lipid Res 2001, 42:1678-1686

39. Tigyi G, Parrill AL: Molecular mechanism of Iysophosphatidic acid action. Prog Lipid Res 2003, 42:498-526

40. Puddu P, Puddu GM, Muscari A: Peroxisome proliferator-activated receptors: are they involved in atherosclerosis progression? Int J Cardiol 2003, 90:133-140 
41. Boord JB, Fazio S, Linton MF: Cytoplasmic fatty acid-binding proteins: emerging roles in metabolism and atherosclerosis. Curr Opin Lipidol 2002, 13:141-147

42. Perrella MA, Pellacani A, Layne MD, Patel A, Zhao D, Schreiber BM, Storch J, Feinberg MW, Hsieh CM, Haber E, Lee ME: Absence of adipocyte fatty acid binding protein prevents the development of accelerated atherosclerosis in hypercholesterolemic mice. FASEB $J$ 2001, 15:1774-1776

43. Layne MD, Patel A, Chen YH, Rebel VI, Carvajal IM, Pellacani A, Ith B, Zhao D, Schreiber BM, Yet SF, Lee ME, Storch J, Perrella MA: Role of macrophage-expressed adipocyte fatty acid binding protein in the development of accelerated atherosclerosis in hypercholesterolemic mice. FASEB J 2001, 15:2733-2735
44. Makowski L, Brittingham KC, Reynolds JM, Suttles J, Hotamisligil GS: The fatty acid-binding protein, aP2, coordinates macrophage cholesterol trafficking and inflammatory activity. Macrophage expression of aP2 impacts peroxisome proliferator-activated receptor gamma and IkappaB kinase activities J Biol Chem 2005, 280:12888-12895

45. St John LC, Bell FP: Arterial fatty acid-binding protein activity associated with dietarily-induced and spontaneously occurring atherosclerosis in the rabbit (Oryctolagus cuniculus). Comp Biochem Physiol B 1990, 97:123-127

46. St John LC, Bell FP: Temporal evaluation of fatty acid-binding protein (FABP) activity in association with the development of atherosclerosis in the rabbit. Comp Biochem Physiol 1992, 102:357-361 